GUIDELINES

\title{
UK guidelines for the management of acute pancreatitis
}

\author{
UK Working Party on Acute Pancreatitis
}

Gut 2005;54(Suppl III):iii1-iii9. doi: 10.1136/gut.2004.057026

\subsection{REVISED RECOMMENDATIONS AND AUDIT STANDARDS \\ 1.1 Recommendations 2003 (*Unchanged from the 1998 recommendations) \\ Diagnosis}

- *The correct diagnosis of acute pancreatitis should be made in all patients within 48 hours of admission (recommendation grade $\mathrm{C}$ ).

- The aetiology of acute pancreatitis should be determined in at least $80 \%$ of cases and no more than $20 \%$ should be classified as idiopathic (recommendation grade $\mathrm{B}$ ).

- Although amylase is widely available and provides acceptable accuracy of diagnosis, where lipase estimation is available it is preferred for the diagnosis of acute pancreatitis (recommendation grade A).

- Where doubt exists, imaging may be used: ultrasonography is often unhelpful and pancreatic imaging by contrast enhanced computed tomography provides good evidence for the presence or absence of pancreatitis (recommendation grade $\mathrm{C}$ ).

\section{Assessment}

- The definitions of severity, as proposed in the Atlanta criteria, should be used. However, organ failure present within the first week, which resolves within 48 hours, should not be considered an indicator of a severe attack of acute pancreatitis (recommendation grade B).

- Available prognostic features which predict complications in acute pancreatitis are clinical impression of severity, obesity, or APACHE II $>8$ in the first 24 hours of admission, and C reactive protein $>150 \mathrm{mg} / \mathrm{l}$, Glasgow score 3 or more, or persisting organ failure after 48 hours in hospital (recommendation grade B).

- Patients with persisting organ failure, signs of sepsis, or deterioration in clinical status 610 days after admission will require computed tomography (recommendation grade $\mathrm{B}$ ).

\section{Prevention of complications}

Correspondence to: Mr CD Johnson, University Surgical Unit, Mail Point 816, Southampton General Hospital, Southampton BH24 4EW, UK; c.d.johnson@ soton.ac.uk .................... about antibiotic prophylaxis against infection of pancreatic necrosis is conflicting and difficult to interpret. Some trials show benefit, others do not. At present there is no consensus on this issue.

- If antibiotic prophylaxis is used, it should be given for a maximum of 14 days (recommen- dation grade $\mathrm{B}$ ). Further studies are needed (recommendation grade $\mathrm{C}$ ).

- The evidence is not conclusive to support the use of enteral nutrition in all patients with severe acute pancreatitis. However, if nutritional support is required, the enteral route should be used if that can be tolerated (recommendation grade A).

- The nasogastric route for feeding can be used as it appears to be effective in $80 \%$ of cases (recommendation grade $\mathrm{B}$ ).

\section{Treatment of gall stones}

- Urgent therapeutic endoscopic retrograde cholangiopancreatography (ERCP) should be performed in patients with acute pancreatitis of suspected or proven gall stone aetiology who satisfy the criteria for predicted or actual severe pancreatitis, or when there is cholangitis, jaundice, or a dilated common bile duct. The procedure is best carried out within the first 72 hours after the onset of pain. All patients undergoing early ERCP for severe gall stone pancreatitis require endoscopic sphincterotomy whether or not stones are found in the bile duct (recommendation grades $\mathrm{B}$ and C).

- Patients with signs of cholangitis require endoscopic sphincterotomy or duct drainage by stenting to ensure relief of biliary obstruction (recommendation grade A).

- All patients with biliary pancreatitis should undergo definitive management of gall stones during the same hospital admission, unless a clear plan has been made for definitive treatment within the next two weeks (recommendation grade $\mathrm{C}$ ).

\section{Management of necrosis}

- *All patients with severe acute pancreatitis should be managed in a high dependency unit or intensive therapy unit with full monitoring and systems support (recommendation grade B).

- All patients with persistent symptoms and greater than $30 \%$ pancreatic necrosis, and those with smaller areas of necrosis and clinical suspicion of sepsis, should undergo image guided fine needle aspiration to obtain
Abbreviations: BSG, British Society of Gastroenterology; $\mathrm{CT}$, computed tomography; EUS, endoscopic ultrasound; $M R$, magnetic resonance; $M R C P$, magnetic resonance cholangiopancreatography; ERCP, endoscopic retrograde cholangiopancreatography; FNA, fine needle aspiration 
material for culture 7-14 days after the onset of pancreatitis (recommendation grade $\mathrm{B}$ ).

- Patients with infected necrosis will require intervention to completely debride all cavities containing necrotic material (recommendation grade $\mathrm{B}$ ).

- The choice of surgical technique for necrosectomy, and subsequent postoperative management, depends on individual features and locally available expertise (recommendation grade $\mathrm{B})$.

\section{Provision of services}

- Every hospital that receives acute admissions should have a single nominated clinical team to manage all patients with acute pancreatitis (recommendation grade C).

- *Management in, or referral to, a specialist unit is necessary for patients with extensive necrotising pancreatitis or with other complications who may require intensive therapy unit care, or interventional radiological, endoscopic, or surgical procedures (recommendation grade $\mathrm{B}$ ).

\subsection{Audit standards in acute pancreatitis}

The Guideline Committee recommend that all patients with acute pancreatitis should be included in prospective audits to encourage improved standards of care in all units. Regionally based audit would allow collection of data on all cases in a referral population. To this end, the following audit standards are proposed.

- Mortality should be lower than $10 \%$ overall, and less than $30 \%$ in severe (that is, complicated) pancreatitis.

- The correct diagnosis of acute pancreatitis should be made in all patients within 48 hours of admission.

- The aetiology of acute pancreatitis should be determined in at least $80 \%$ of cases and no more than $20 \%$ should be classified as idiopathic.

- Severity stratification should be made in all patients within 48 hours of diagnosis.

- Patients with persisting organ failure, signs of sepsis, or deterioration in clinical status 6-10 days after admission should have computed tomography using a dedicated pancreas protocol.

- All patients with severe acute pancreatitis should be managed in a high dependency unit or intensive therapy unit with full monitoring and systems support.

- Antibiotic prophylaxis against infection of the necrosis should not be given for more than 14 days in the absence of positive cultures.

- All patients with biliary pancreatitis should undergo definitive management of gall stones during the same hospital admission, unless a clear plan for definitive treatment within the next two weeks has been made.

- Patients with extensive necrotising pancreatitis or with other complications who may require ITU care, or interventional radiological, endoscopic, or surgical procedures, should be managed in, or referred to, a specialist unit.

- Radiological facilities should be available to permit ultrasound examination of the gall bladder within 24 hours of diagnosis of acute pancreatitis. Specialist units will have access at any time to contrast enhanced helical or multislice computed tomography or magnetic resonance imaging, percutaneous image guided aspiration and drainage techniques, and angiography for the early assessment and treatment of abdominal and other complications.
- Facilities and expertise should be available for ERCP to be performed at any time for common bile duct evaluation followed by sphincterotomy and stone extraction or stenting, as required.

\subsection{INTRODUCTION}

In 1998 the British Society of Gastroenterology (BSG) published UK guidelines on the management of acute pancreatitis. ${ }^{1}$ A planned revision after two years was anticipated. The BSG as the prime sponsor of these guidelines initiated a review process in 2000. These guidelines are part of a series sponsored by the BSG, and a policy decision was taken in that organisation to modify the format of the guidelines, to enable the dissemination of summary documents listing the main conclusions, recommendations, and audit standards, with a subsidiary document reviewing the evidence in detail. The present document uses this new format; in addition it focuses on developments since 1998. Although some revisions are necessary, the main evidence base was well reviewed previously, and remains valuable.

Three further documents provide a substantial review of the evidence. ${ }^{2-4}$ An ad hoc consensus group reported in 1999 and identified some important modifications in the definition of severity and complications. Their report ${ }^{2}$ also considered surgical treatment which had not been discussed in the 1998 guidelines. Recently, a working party of the World Association of Gastroenterology has produced a further set of guidelines for the management of acute pancreatitis, ${ }^{24}$ and the International Association of Pancreatology has published guidelines on the surgical management of acute pancreatitis. ${ }^{3}$

The present document represents the view of the UK societies that contributed to its development, together with comments from invited overseas participants. The evidence supporting these views can in large part be found in the documents cited above but specific reference is made to clinical evidence where appropriate, to support differences of opinion or to update the evidence base. These guidelines should be reviewed after no more than five years and should be applied with appropriate consideration of changes in the evidence base.

\subsection{EPIDEMIOLOGY}

The incidence of acute pancreatitis in the UK appears to be rising. This is certainly true in Scotland ${ }^{5}$ and appears also to be the case in the South of England. ${ }^{67}$ Incidence ranges in the UK from 150 to 420 cases per million population. ${ }^{57}$

\subsection{DEFINITION OF SEVERITY}

The Atlanta criteria for severity are widely accepted. ${ }^{8}$ The summary of these criteria in the World Association guidelines is inadequate and the reader is referred to the original publication. Two points should be noted. Firstly, there is a distinction between severe acute pancreatitis defined by the presence of a complication, and predicted severe acute pancreatitis as determined by multifactor scoring systems or other predictive tests. Secondly, the definition of acute pseudocyst is a fluid collection persisting for more than four weeks, arising from an attack of acute pancreatitis.

The Santorini consensus conference highlighted the difficulty of distinguishing pseudocyst from other peripancreatic collections using computed tomography (CT) alone. It is recommended that definite imaging evidence of fluid (as opposed to necrotic tissue) be obtained using ultrasound or magnetic resonance (MR) before this diagnosis is considered. In clinical practice it is wise to consider all localised collections following necrotising pancreatitis to be localised necrosis until proved otherwise (evidence category $\mathrm{C}$ ). 
A further modification to the Atlanta criteria is proposed in a recent publication from Glasgow. ${ }^{9}$ In a prospective observational study it was found that patients with organ failure that had persisted for more than 48 hours had a mortality rate in excess of $50 \%$; by contrast, patients with organ failure that resolved within 48 hours had a mortality rate of zero. This observation has been confirmed in a larger group of patients recruited across the UK. ${ }^{10}$

\section{Recommendation}

- The definitions of severity, as proposed in the Atlanta criteria, should be used. However, organ failure present within the first week, which resolves within 48 hours, should not be considered an indicator of a severe attack of acute pancreatitis (recommendation grade B).

\subsection{IDIOPATHIC ACUTE PANCREATITIS}

In most series, gall stone disease represents approximately half the cases of acute pancreatitis, and $20-25 \%$ are related to alcohol abuse. A small number of cases are caused by a variety of other causes but a residual group has no obvious cause and is labelled "idiopathic".

The diagnosis of idiopathic pancreatitis should not be accepted in the absence of a vigorous search for gall stones. As a minimum, it is necessary to obtain at least two good quality ultrasound examinations. After one negative ultrasound examination, the most sensitive test for diagnosis of gall stones that may have been missed remains a further ultrasound examination. ${ }^{11} 12$

The advent of endoscopic ultrasound (EUS) and magnetic resonance cholangiopancreatography (MRCP) increased the range of tests available to search for a cause of acute pancreatitis. There is little evidence to support their routine use in all cases of idiopathic acute pancreatitis. In recurrent cases, EUS may detect microlithiasis in the gall bladder or common bile duct, and MRCP will demonstrate most duct stones and ductal anomalies such as pancreas divisum.

EUS is as accurate and safer than endoscopic retrograde cholangiopancreatography (ERCP) for the detection of common bile duct stones. ${ }^{13}$ The technique requires considerable expertise and is not widely available in the UK; urgent action is required to provide access to EUS on a regional or subregional basis. EUS can be used to identify patients who require therapeutic ERCP.

Bile sampling may be the only way to identify patients with recurrent acute pancreatitis due to microlithiasis. Biliary manometry (used for the identification of sphincter of Oddi dysfunction) carries a significant risk of precipitating acute pancreatitis and should be performed only in specialist units. Careful patient selection is required to identify those who may benefit from manometry and subsequent treatment. ${ }^{14}$

Fasting blood lipids and calcium concentrations should be determined. Early and convalescent viral antibody titres (mumps, Coxsackie B4, and others) may identify a possible cause although no specific therapy will result. The possibility of an underlying neoplasm or chronic pancreatitis should be considered and investigated as appropriate.

The previous UK guidelines recommended that no more than $20-25 \%$ of patients should be classified as idiopathic. Some authors report values as low as $10 \% .{ }^{15-18}$ However, it seems that such a low value is unrealistic in general clinical practice in the UK.

Table 1 shows a suggested plan of investigation of patients with acute pancreatitis, to determine the cause.
Table 1 Investigations helpful to determine the cause of acute pancreatitis

\begin{tabular}{|c|c|}
\hline History & $\begin{array}{l}\text { Previous gall stones } \\
\text { Alcohol intake } \\
\text { Family history* } \\
\text { Drug intake } \\
\text { Exposure to known viral causes or } \\
\text { prodromal symptoms }\end{array}$ \\
\hline $\begin{array}{l}\text { Initial investigations } \\
\text { (acute phase) }\end{array}$ & $\begin{array}{l}\text { Pancreatic enzymes in plasma } \\
\text { Liver function tests } \\
\text { Ultrasound of gall bladder }\end{array}$ \\
\hline $\begin{array}{l}\text { Follow up investigations } \\
\text { (recovery phase) }\end{array}$ & $\begin{array}{l}\text { Fasting plasma lipids } \\
\text { Fasting plasma calcium } \\
\text { Viral antibody titres } \\
\text { Repeat biliary ultrasound } \\
\text { MRCP } \\
\text { CT (helical or multislice with } \\
\text { pancreas protocol) }\end{array}$ \\
\hline $\begin{array}{l}\text { Further investigations (usually } \\
\text { appropriate for recurrent } \\
\text { idiopathic acute pancreatitis) }\end{array}$ & $\begin{array}{l}\text { Further ultrasound } \\
\text { Endoscopic ultrasound } \\
\text { Autoimmune markers } \\
\text { ERCP-bile for crystals-bile and } \\
\text { pancreatic cytology } \\
\text { ERCP-bile and pancreatic cytology } \\
\text { Sphincter of Oddi manometry } \\
\text { Pancreatic function tests to exclude } \\
\text { chronic pancreatitis }\end{array}$ \\
\hline
\end{tabular}

*Genetic analysis is only indicated in the presence of a family history of one or more of the following: acute pancreatitis, recurrent undiagnosed abdominal pain, pancreatic carcinoma, or type 1 diabetes mellitus. $M R C P$, magnetic resonance cholangiopancreatography; ERCP, endoscopic retrograde cholangiopancreatography.

Modified from the World Association guidelines. ${ }^{3}$

\section{Recommendation}

- The aetiology of acute pancreatitis should be determined in at least $80 \%$ of cases and no more than $20 \%$ should be classified as idiopathic (recommendation grade B).

\subsection{DIAGNOSIS OF ACUTE PANCREATITIS}

Clinical features (abdominal pain and vomiting) together with elevation of plasma concentrations of pancreatic enzymes are the cornerstones of diagnosis. Pancreatic enzymes are released into the circulation during an acute attack. Levels peak early, and decline over 3-4 days. "An important concept derives from this: the diagnosis of acute pancreatitis should not rely on arbitrary limits of values 3 or 4 times greater than normal, but values should be interpreted in light of the time since the onset of abdominal pain". ${ }^{4}$

The half life of elevated amylase is shorter than that of lipase. Because it persists longer after the onset of the attack and because the pancreas is the only source of lipase, estimation of plasma lipase has slightly superior sensitivity and specificity and greater overall accuracy than amylase.

Plain radiographs contribute little to the diagnosis of acute pancreatitis. Ultrasound may show pancreatic swelling but the pancreas is visualised in only $25-50 \%$ of patients with acute pancreatitis. The value of ultrasonography lies in its ability to demonstrate gall bladder stones and dilatation of the common bile duct, as well as other pathology unrelated to the pancreas such as abdominal aortic aneurysm. CT is occasionally indicated for diagnosis, if clinical and biochemical findings are inconclusive, especially when abdominal signs raise the possibility of an alternative abdominal emergency, such as a perforation or infarction of the bowel. 


\section{Recommendations}

- Although amylase is widely available and provides acceptable accuracy of diagnosis, where lipase is available it is preferred for the diagnosis of acute pancreatitis (recommendation grade A).

- Where doubt exists, imaging may be used: ultrasonography is often unhelpful and pancreatic imaging by contrast enhanced CT provides good evidence for the presence or absence of pancreatitis (recommendation grade C).

\subsection{PREDICTION OF SEVERITY}

Table 2 outlines features that predict a severe attack of acute pancreatitis. There is agreement that there is still a need for an early objective measure of severity (recommendation grade C). Clinical examination in the first 24 hours of admission although specific lacks sensitivity and hence is unreliable and should be supported by objective measures (recommendation grade A).

It is clear that $C$ reactive protein is a useful indicator of severity, more than 48 hours after onset of symptoms. The Santorini consensus and the World Association guidelines recommend a cut off of $150 \mathrm{mg} / \mathrm{l}$ and this value should replace the level recommended in the 1998 guidelines.

Immediate assessment should include clinical evaluation, particularly of any cardiovascular, respiratory, and renal compromise, body mass index, chest $x$ ray, and APACHE II score. The presence of any organ failure should be documented.

After 24 hours in hospital, clinical assessment and documentation of organ failure are required. The APACHE II score should be repeated to record the worst values in the first 24 hours. The Glasgow score may be applied at this stage although it will not be complete until 48 hours. Taking account of the time since onset of symptoms, measurement of $\mathrm{C}$ reactive protein may be useful at this time.

By 48 hours after admission, the patient's clinical state, Glasgow score, and C reactive protein can all contribute to the assessment of severity, in addition to the features noted earlier.

Activation peptides of pancreatic enzymes, in particular trypsinogen activation peptide and carboxypeptidase activation peptide, have been shown to provide good prognostic information in acute pancreatitis. ${ }^{19-22}$ However, rapid assays suitable for clinical use are not yet available so activation peptides are not listed in table 2 .

Table 2 Features that may predict a severe attack, present within 48 hours of admission to hospital

\begin{tabular}{|c|c|}
\hline Initial assessment & $\begin{array}{l}\text { Clinical impression of severity } \\
\text { Body mass index }>30 \\
\text { Pleural effusion on chest radiograph } \\
\text { APACHE II score }>8\end{array}$ \\
\hline $24 \mathrm{~h}$ after admission & $\begin{array}{l}\text { Clinical impression of severity } \\
\text { APACHE II score }>8 \\
\text { Glasgow score } 3 \text { or more } \\
\text { Persisting organ failure, especially if multiple } \\
\mathrm{C} \text { reactive protein }>150 \mathrm{mg} / \mathrm{l}\end{array}$ \\
\hline $48 \mathrm{~h}$ after admission & $\begin{array}{l}\text { Clinical impression of severity } \\
\text { Glasgow score } 3 \text { or more } \\
\mathrm{C} \text { reactive protein }>150 \mathrm{mg} / \mathrm{l} \\
\text { Persisting organ failure for } 48 \mathrm{~h} \\
\text { Multiple or progressive organ failure }\end{array}$ \\
\hline
\end{tabular}

Subsequent monitoring of progress depends on repeated clinical evaluation, regular estimation of $\mathrm{C}$ reactive protein levels (twice weekly) and CT when indicated. There is no evidence to support the use of repeated APACHE II scores for monitoring progress.

\section{Recommendation}

- Available prognostic features which predict complications in acute pancreatitis are clinical impression of severity, obesity, or APACHE II $>8$ in the first 24 hours of admission, and C reactive protein levels $>150 \mathrm{mg} / \mathrm{l}$, Glasgow score 3 or more, or persisting organ failure after 48 hours in hospital (recommendation grade B).

\subsection{CT IN ACUTE PANCREATITIS}

\subsection{Initial assessment by CT}

In the UK it is not current practice to perform early CT for the detection and staging of severe cases of acute pancreatitis. Despite a study that showed no greater mortality after early $\mathrm{CT}^{23}{ }^{24}$ anxieties persist over the potential for extension of necrosis and exacerbation of renal impairment following the use of intravenous contrast media. Furthermore, it is not clear how soon the full extent of the necrotic process will occur, but it is at least four days after the onset of symptoms ${ }^{25}$ and early CT may therefore underestimate the final severity of the disease. Finally, unless some management decision is required based on the extent of necrosis (for example, use of prophylactic antibiotics), CT for staging is unlikely to materially affect the management of patients with acute pancreatitis during the first week of the illness. If CT staging of acute pancreatitis is required, the CT severity index, as proposed by Balthazar and colleagues, ${ }^{26}$ should be used (table 3). There is also evidence that the site of pancreatic necrosis is an important prognostic factor with a worse outcome observed in patients with necrosis affecting the head of the pancreas. ${ }^{27} 28$ The findings of free intraperitoneal fluid and extensive peripancreatic fat stranding (which can be demonstrated on non-contrast scans) have also been demonstrated to be associated with worse outcome. ${ }^{27} 29$ The role of CT in the evaluation of severe pancreatitis has recently been reviewed ${ }^{30}$

Patients with persisting organ failure, or in whom new organ failure develops, and in those with persisting pain and signs of sepsis, will require evaluation by dynamic contrast enhanced CT. CT evidence of necrosis correlates well with the risk of other local and systemic complications. ${ }^{23} 2431$ The decision to perform CT will usually be taken after approximately one week of hospital admission.

\section{Recommendation}

- Patients with persisting organ failure, signs of sepsis, or deterioration in clinical status 6-10 days after admission will require $\mathrm{CT}$ (recommendation grade B).

\subsection{CT protocol}

Inadequate information often results from poor CT technique. A pancreas protocol will ensure best use of resources. Spiral or multislice CT is required for assessment of acute pancreatitis. The speed and flexibility of these scanners are beneficial for these sick patients. Precise technique will depend on scanner specifications but all patients should be given approximately $500 \mathrm{ml}$ of oral contrast by mouth or nasogastric tube. An initial scan without intravenous contrast 


\begin{tabular}{|c|c|}
\hline \multicolumn{2}{|c|}{ Table 3 Computed tomography (CT) grading of severity } \\
\hline \multicolumn{2}{|l|}{$\mathrm{CT}$ grade } \\
\hline (A) Normal pancreas & 0 \\
\hline (B) Oedematous pancreatitis & 1 \\
\hline (C) B plus mild extrapancreatic changes & 2 \\
\hline $\begin{array}{l}\text { (D) Severe extrapancreatic changes including } \\
\text { one fluid collection }\end{array}$ & 3 \\
\hline $\begin{array}{l}\text { (E) Multiple or extensive extrapancreatic } \\
\text { collections }\end{array}$ & 4 \\
\hline \multicolumn{2}{|l|}{ Necrosis } \\
\hline None & 0 \\
\hline$<$ One third & 2 \\
\hline$>$ One third, <one half & 4 \\
\hline$>$ Half & 6 \\
\hline \multicolumn{2}{|l|}{$\mathrm{CT}$ severity index $=\mathrm{CT}$ grade+necrosis score } \\
\hline & Complications \\
\hline $0-3$ & \\
\hline $4-6$ & $35 \%$ \\
\hline $7-10$ & $92 \%$ \\
\hline & Deaths \\
\hline $0-3$ & $3 \%$ \\
\hline $4-6$ & $6 \%$ \\
\hline $7-10$ & $17 \%$ \\
\hline
\end{tabular}

allows pancreatic levels to be identified and demonstrates the extent of peripancreatic change. A post contrast series is obtained after a bolus intravenous injection of $100 \mathrm{ml}$ of nonionic contrast delivered at $3 \mathrm{ml} / \mathrm{s}$ using a power injector. Images through the pancreatic bed should be obtained using thin collimation ( $5 \mathrm{~mm}$ or less) commencing approximately 40 seconds after the start of the injection. Non-opacification of at least one third of the pancreas, or an area $>3 \mathrm{~cm}$ diameter, indicates necrosis. A second series of images beginning at 65 seconds after injection (portal venous phase) will give information about patency of the main peripancreatic veins. CT of the pancreas without intravenous contrast enhancement gives suboptimal information and should be avoided.

\subsection{Follow up CT}

Patients with mild pancreatitis, or patients with a CT severity index of $0-2$, require further CT only if there is a change in the patient's clinical status that suggests a new complication.

In patients with a CT severity index of 3-10, additional follow up scans are recommended only if the patient's clinical status deteriorates or fails to show continued improvement. ${ }^{4}$ However, some would advise a single further scan in patients who make an apparently uncomplicated recovery, before the patient is discharged from hospital, to detect the presence of asymptomatic complications such as pseudocyst or arterial pseudoaneurysm. ${ }^{4}$

\subsection{INITIAL MANAGEMENT AND PREVENTION OF COMPLICATIONS}

Adequate prompt fluid resuscitation is crucial in the prevention of systemic complications. Although the majority of patients will have mild disease that resolves spontaneously, it is difficult to detect patients at risk of complications early in the hospital admission. There is some evidence that early oxygen supplementation and fluid resuscitation may be associated with resolution of organ failure, ${ }^{32}$ and early resolution of organ failure is associated with very low mortality, ${ }^{90}$ so it is appropriate to ensure that all patients with acute pancreatitis receive adequate oxygen and fluids until it is clear that the danger of organ failure has passed. Oxygen saturation should be measured continuously and supplemental oxygen should be administered to maintain an arterial saturation greater than $95 \%$. Fluids are given intravenously (crystalloid or colloid as required) to maintain urine output $>0.5 \mathrm{ml} / \mathrm{kg}$ body weight. The rate of fluid replacement should be monitored by frequent measurement of central venous pressure in appropriate patients. It is wise to treat every patient aggressively until disease severity has been established. ${ }^{4}$

\subsection{SPECIFIC DRUG THERAPY}

There is no proven therapy for the treatment of acute pancreatitis. ${ }^{2}$ Despite initial encouraging results, antiproteases such as gabexate, antisecretory agents such as octreotide, and anti-inflammatory agents such as lexipafant have all proved disappointing in large randomised studies. ${ }^{33-35}$

\subsection{PROPHYLACTIC ANTIBIOTICS}

Infection of necrosis is the most serious local complication of acute pancreatitis and is associated with a high mortality rate $(40 \%)$. There has been considerable interest in the potential to prevent infection by administration of prophylactic antibiotics.

The available studies $^{36-41}$ are not individually conclusive although some have shown benefit from antibiotic prophylaxis. These studies used different antibiotic drugs, different selection criteria, and different durations of treatment. Definitions of severe disease vary between the trials but in each the aim was to deliver antimicrobial prophylaxis to patients with severe acute pancreatitis with evidence of pancreatic necrosis. Duration of prophylaxis was relatively long (up to 14 days). All of these studies were small, and several did not have sufficient power to assess the effect of antibiotics on mortality rate. Combination of the numbers observed in these studies suggests that there may be a significant reduction in complications and deaths in patients with predicted severe acute pancreatitis treated with prophylactic antibiotics (table 4 ) but this ignores the major inconsistencies within and between these trials. ${ }^{36-41}$

The difficulties of interpretation are examined in detail in a recent Cochrane review. ${ }^{42}$ The trials reviewed used different antibiotics given for varying periods. There is variation in the findings between studies, with different end points showing large treatment effects in different trials. This heterogeneity makes meta-analysis less reliable and indicates the need for further double blind randomised controlled trials.

Mortality rates and infected necrosis were assessed in four studies which showed significance in favour of prophylactic antibiotics (odds ratio $0.32(\mathrm{p}=0.02)$ and odds ratio 0.51 $(p=0.04)$, respectively). Extrapancreatic infection was evaluated in three studies but showed no significant advantage for therapy (odds ratio 0.47, $\mathrm{p}=0.05$ ). Operative treatment data were available in three studies but surgery rates were not significantly reduced (odds ratio $0.55, \mathrm{p}=0.08$ ). Fungal infections showed no strongly increased preponderance with therapy (odds ratio 0.83, $\mathrm{p}=0.7$ ) but there were no data on infection with resistant organisms. Duration of hospital stay could only be evaluated in two studies and was not significantly different. Subgroup analyses planned for the influence on outcome measures of the antibiotic regimen, the time of commencement of therapy in relation to symptom onset and/or hospitalisation, duration of therapy, and aetiology could not be performed as no data were available.

A more recent trial from Germany ${ }^{37}$ which compared ciprofloxacin/metronidazole and placebo is the only double blind placebo controlled trial published to date. The results do not support the use of prophylactic antibiotics. This study was stopped after interim analysis of 76 patients with necrosis (of a total of 114 patients randomised) showed no differences in the primary outcomes of infected necrosis, systemic complications, and mortality rates. However, infectious complications, multiple organ failure, sepsis, or systemic inflammatory response syndrome occurred in only $28 \%$ of patients who received antibiotics compared with $46 \%$ of the placebo group. All 
patients with these features received treatment with antibiotics As a consequence, non-study antibiotics were started in nearly half of the placebo group after a median of five days which introduces a significant bias against the treatment effect and makes interpretation of this trial difficult.

Antibiotics are unlikely to be affect outcome in patients without extensive necrosis. The risk of infected necrosis and infection in the peripancreatic tissue is very small when there is less than $30 \%$ necrosis. Thus it is reasonable to suppose, although no evidence exists at present to support this view, that prophylactic antibiotic therapy should be considered only for patients with CT evidence of more than $30 \%$ necrosis of the pancreas.

There remains no consensus view on the value of antibiotic prophylaxis. Even among proponents of prophylaxis there is little agreement on either the choice of agent or the duration of therapy. Although concerns have been expressed about the risk of encouraging selective growth of resistant organisms, the results of bacterial culture of fine needle aspirates from areas of pancreatic necrosis in the randomised trials reported to date have not addressed this issue. Rates of fungal infection are less than $10 \%$ and similar in treatment and control groups. In the trials, prophylaxis has usually been for a defined period (table 4). If antibiotic prophylaxis is used, it seems sensible to limit the duration of prophylaxis to 7-14 days. Treatment should not be continued beyond that time without evidence of infection provided by bacterial growth on culture. When such evidence exists, appropriate antibiotic therapy should be guided by the results of sensitivity testing in accordance with critical care medicine guidelines. ${ }^{43}$

\subsection{SELECTIVE GUT DECONTAMINATION}

No further evidence has been published to support the one large randomised controlled trial ${ }^{44}$ which has been conducted in patients with severe pancreatitis, to examine the effect of selective gut decontamination, in combination with intravenous antibiotics, on outcome in acute pancreatitis. In that study there was no statistically significant reduction in mortality rate. It is not clear whether the reported benefits of treatment arose from the use of intravenous antibiotics or

\section{Recommendation}

- The evidence to enable a recommendation about antibiotic prophylaxis against infection of pancreatic necrosis is conflicting and difficult to interpret. Some trials show benefit, others do not. At present there is no consensus on this issue. If antibiotic prophylaxis is used, it should be given for a maximum of 14 days (recommendation grade B). Further studies are needed (recommendation grade $\mathrm{C}$ ). from gut decontamination. Therefore, at present, selective gut decontamination cannot be recommended in patients with acute pancreatitis.

\subsection{ENTERAL NUTRITION}

Nutritional support was not considered in the previous UK guidelines. The Santorini consensus and the World Association guidelines comment on five studies that demonstrate the safety of enteral feeding in patients with acute pancreatitis. There is no benefit from enteral feeding in mild pancreatitis, and these patients need have no dietary restrictions. Artificial feeding may be used in acute pancreatitis either to prevent complications or to provide long term nutritional support.

In patients with severe disease, oral intake is inhibited by nausea; the acute inflammatory response is associated with impaired gut mucosal barrier function. It has been suggested that nutritional support may help to preserve mucosal function and limit the stimulus to the inflammatory response. In these circumstances enteral feeding seems to be safer than parenteral feeding, with fewer septic complications. ${ }^{45}{ }^{46}$ It is also cheaper. These findings are supported by a further small study which demonstrated minor clinical advantages in recovery time in patients who received early enteral nutrition compared with those receiving parenteral nutrition. ${ }^{47}$ However, another randomised comparison, of enteral feeding versus no nutritional support, failed to demonstrate any effect of enteral feeding on markers of the inflammatory response. ${ }^{48}$

The use of enteral feeding may be limited by ileus. If this persists for more than five days, parenteral nutrition will be required.

Various formulations have been used in pancreatitis, but no comparative studies exist to determine the relative merits of standard, partially digested, elemental, or "immune enhanced" formulations.

The majority of studies have reported enteral feeding via a nasojejunal tube; there is some evidence that nasogastric feeding may be feasible in up to $80 \%$ of cases. ${ }^{27}$ Caution should be used when administering nasogastric feed to patients with impaired consciousness because of the risk of aspiration of refluxed feed.

\section{Recommendation}

- The evidence is not conclusive to support the use of enteral nutrition in all patients with severe acute pancreatitis. However, if nutritional support is required, the enteral route should be used if that can be tolerated (grade A). The nasogastric route for feeding can be used as it appears to be effective in $80 \%$ of cases (grade B).

Table 4 Trials of antibiotic prophylaxis against untreated controls in severe acute pancreatitis

\begin{tabular}{|c|c|c|c|c|c|c|}
\hline \multirow[b]{2}{*}{ Reference } & \multirow[b]{2}{*}{ Agent } & \multirow{2}{*}{$\begin{array}{l}\text { Duration } \\
\text { (days) }\end{array}$} & \multicolumn{2}{|c|}{ Pancreatic infection } & \multicolumn{2}{|l|}{ Deaths } \\
\hline & & & Treated & Control & Treated & Control \\
\hline Pederzoli $^{39}$ & Imipenem & 14 & $5 / 41$ & $10 / 33$ & $3 / 41$ & $4 / 33$ \\
\hline Sainio40 & Cefuroxime & 14 & $9 / 30$ & $12 / 30$ & $1 / 30$ & $7 / 30$ \\
\hline Delcenserie $^{36}$ & Ceftazidime, amikacin, metronidazole & 10 & $0 / 11$ & $3 / 12$ & $1 / 11$ & $3 / 12$ \\
\hline Schwarz ${ }^{41}$ & Ofloxacin, metronidazole & $>10$ & $8 / 13$ & $7 / 13$ & $0 / 13$ & $3 / 13$ \\
\hline Nordback $^{38}$ & Imipenem/cilastatin & Not stated & $2 / 25$ & $14 / 33$ & $2 / 25$ & $5 / 33$ \\
\hline Isenmann ${ }^{37}$ & Ciprofloxacin, metronidazole & $14(3-23)$ & $7 / 58$ & $5 / 56$ & $3 / 58$ & $4 / 56$ \\
\hline Total & & & $31 / 178$ & $51 / 177$ & $10 / 178$ & $26 / 177$ \\
\hline
\end{tabular}

Values given are the numbers of infections or deaths and the numbers in each group. (The Isenmann study was placebo controlled: $46 \%$ of placebo group received non-trial antibiotics after a median of five days).

Significantly fewer infections $\left(\chi^{2}=5.87, p<0.02\right)$ and deaths $\left(\chi^{2}=7.06, p<0.01\right)$ were seen overall in patients treated with antibiotics. 


\subsection{GALL STONE PANCREATITIS AND TREATMENT OF GALL STONES}

\subsection{Endoscopic sphincterotomy}

There are now three randomised trials ${ }^{49-51}$ of endoscopic sphincterotomy versus no treatment in patients with gall stones and predicted severe acute pancreatitis. These are discussed in detail in the Santorini consensus and the World Association guidelines, together with a further randomised trial published only in abstract form.

\section{Recommendation}

- Urgent therapeutic ERCP should be performed in patients with acute pancreatitis of suspected or proven gall stone aetiology who satisfy the criteria for predicted or actual severe pancreatitis, or when there is cholangitis, jaundice, or a dilated common bile duct. The procedure is best carried out within the first 72 hours after the onset of pain. All patients undergoing early ERCP for severe gall stone pancreatitis require endoscopic sphincterotomy whether or not stones are found in the bile duct (recommendation grades $B$ and C). Patients with signs of cholangitis require endoscopic sphincterotomy or duct drainage by stenting to ensure relief of biliary obstruction (recommendation grade A).

\subsection{Timing of cholecystectomy}

After an attack of mild acute pancreatitis, patients with gall stones should undergo definitive treatment in order to prevent recurrence of pancreatitis. There is a significant risk of further acute pancreatitis which may be severe and life threatening. Definitive treatment of gall stones will usually be by cholecystectomy, either laparoscopic or open, with operative cholangiography, unless there are significant risk factors for operative treatment. For unfit patients, endoscopic sphincterotomy alone is adequate treatment. All patients who have gall stones and acute pancreatitis require imaging of the bile duct. The Working Group felt strongly that definitive treatment should not be delayed more than two weeks after discharge from hospital, and that it is preferable to achieve this goal during the same admission to avoid potential delay from cancellation. Such delay exposes the patient to a risk of potentially fatal recurrent acute pancreatitis.

Cholecystectomy should be delayed in patients with severe acute pancreatitis until signs of lung injury and systemic disturbance have resolved.

\section{Recommendation}

- All patients with biliary pancreatitis should undergo definitive management of gall stones during the same hospital admission, unless a clear plan has been made for definitive treatment within the next two weeks (recommendation grade C).

\subsection{CRITICAL CARE MANAGEMENT}

Patients with severe acute pancreatitis have an increased risk of death. Patients who die usually have evidence of organ failure. The group at greatest risk is those patients with organ failure persisting for more than 48 hours during the first week. ${ }^{92}$ All patients with predicted severe acute pancreatitis should be monitored closely, preferably in a high dependency unit. When there is organ dysfunction or organ failure, supportive treatment should be provided in an appropriate critical care facility.

\section{Recommendation}

- All patients with severe acute pancreatitis should be managed in a high dependency unit or intensive therapy unit with full monitoring and systems support (recommendation grade B).

\subsection{SURGICAL TREATMENT FOR ACUTE PANCREATITIS AND PANCREATIC NECROSIS}

Most patients with acute pancreatitis do not require surgical treatment of the pancreatic disease although many will subsequently undergo cholecystectomy. Occasionally, the diagnosis will be made at emergency laparotomy for suspected peritonitis although increasingly CT is used to obtain a preoperative diagnosis and avoid unnecessary laparotomy. Expert consensus ${ }^{2}{ }^{4}$ is that in this situation cholecystectomy with operative cholangiography should be performed. If stones are found in the common bile duct these should be removed if possible. The minimum manoeuvre would be external tube drainage of the common bile duct.

\subsection{Indications for intervention in pancreatic necrosis}

The decision to intervene depends on the clinical picture (evidence of sepsis) and demonstration by CT of pancreatic or peripancreatic necrosis. There is agreement that all patients with infected necrosis require intervention by radiological or surgical drainage. ${ }^{2-4}$ The infection may be diagnosed either by the presence of gas within the pancreatic collection or by fine needle aspiration. Patients with persistent symptoms for more than seven days, and greater than 30\% pancreatic necrosis, and those with smaller areas of necrosis and clinical suspicion of sepsis should undergo image guided fine needle aspiration (FNA) to obtain material for culture. ${ }^{3}$ FNA is safe, and has very few complications, as well as high sensitivity and specificity for the detection of infection ${ }^{53-55}$

Patients with apparently sterile necrosis may occasionally require operation but this is relatively uncommon.

\section{Recommendations}

- All patients with persistent symptoms and greater than $30 \%$ pancreatic necrosis, and those with smaller areas of necrosis and clinical suspicion of sepsis, should undergo image guided FNA to obtain material for culture 7-14 days after the onset of the pancreatitis (recommendation grade B).

- Patients with infected necrosis will require intervention to completely debride all cavities containing necrotic material (recommendation grade B).

16.2 Choice of interventional or surgical procedure There is controversy over the roles of radiological drainage and surgical necrosectomy in the management of infected pancreatic and peripancreatic necrosis. Standard surgical practice is that all patients with infected necrosis should 
undergo necrosectomy. This has been challenged by retrospective studies from referral centres describing good outcome in patients managed by percutaneous drains.

\subsubsection{Radiological drainage}

In one report, 31 patients with pancreatic abscess were managed by percutaneous drainage. There was a $31 \%$ primary success rate. ${ }^{56}$ Freeny et al also reported encouraging results $^{57}$ : in 34 patients nearly half had successful treatment by catheter drainage and only nine required surgical drainage. This suggests that percutaneous wide bore drainage may be sufficient for the treatment of infected necrosis. However, many surgeons are sceptical that solid necrotic tissue can be evacuated along a drain of any size, unless the necrotic tissue has already softened and liquefied, as in pancreatic abscess.

\subsubsection{Surgical debridement}

Thorough debridement of necrotic tissue is essential during any surgical intervention. Following this, the abdomen may be closed over drains, packed and left open, or closed over drains and the pancreatic cavity irrigated. There is no clear evidence to support one or other of these techniques over the others. Indeed, the available evidence suggests that overall mortality rate is similar with all three approaches but the postoperative mortality rate depends on selection criteria for operation. ${ }^{58}$ One randomised comparison was discontinued early because more complications were seen with closed drainage and irrigation than in those treated with closed drainage alone. ${ }^{59}$ The choice of surgical technique can be based on clinically derived experience and local expertise.

A new approach for surgical debridement of infected necrosis offers the potential to debride necrotic tissue with minimal systemic disturbance, by approaching the cavity along the track of a percutaneously placed drain..$^{60}$ The cavity is then debrided piecemeal with an operating nephroscope. Several sessions may be required in order to achieve complete debridement. Postoperatively the cavity is continuously irrigated. This approach has not been tested against the traditional surgical approach in a randomised trial but comparison with historical controls suggests that it may be as safe as open operation. Further evidence is required to evaluate the place of this technique in the management of pancreatic necrosis.

\section{Recommendation}

- The choice of surgical technique for necrosectomy, and subsequent postoperative management depends on individual features and locally available expertise (recommendation grade B).

\subsection{OTHER LOCAL COMPLICATIONS}

Local complications of pancreatic necrosis, such as pseudocyst and pancreatic abscess, often require surgical, endoscopic, or radiological intervention. It is difficult to give precise guidance in this area because of the variations in patients, anatomical disturbance, and local expertise. Reported results of surgical and endoscopic drainage are similar, ${ }^{2}{ }^{4}$ and percutaneous techniques may be successful in appropriate cases. Each case should be managed in an individualised way, by a multidisciplinary specialist pancreatic team, taking account of these features.

\subsection{SPECIALIST TREATMENT AND THE PROVISION OF SERVICES}

The requirement for specialist care for patients with severe acute pancreatitis, and the definition of a specialist team (table 5), are unchanged from the 1998 guidelines. Every hospital that receives acute admissions should have a single nominated clinical team to manage all patients with acute pancreatitis. If the full range of specialist services is not available in their hospital, the nominated team should coordinate local management where possible, and referral to a specialist unit where appropriate. The presence of $>30 \%$ necrosis is a useful marker of the most severe cases and should prompt discussion with or referral to a specialist unit. In every hospital, the nominated team should maintain regular and prospective audit of all patients with acute pancreatitis. This audit activity should be coordinated at a regional level.

\section{Recommendations}

- Every hospital that receives acute admissions should have a single nominated clinical team to manage all patients with acute pancreatitis (recommendation grade C).

- Management in, or referral to, a specialist unit is necessary for patients with extensive necrotising pancreatitis ( $>30 \%$ necrosis) or with other complications who may require ITU care, or interventional radiological, endoscopic, or surgical procedures (recommendation grade B).

\subsection{ACKNOWLEDGEMENTS}

\section{Contributors}

CD Johnson, Chairman, Pancreatic Section, BSG; R Charnley, Pancreatic Society; B Rowlands, ASGBI; R Carter, AUGIS; C Bassi; A Chalmers; CW Imrie; M Larvin; CJ Mitchell; JP Neoptolemos; A Siriwardena; E Aly, G Butturini, J Kelly.

Table 5 Features of a specialist unit for the treatment of severe acute pancreatitis

\begin{tabular}{ll}
\hline Clinicians & $\begin{array}{l}\text { A multidisciplinary team of specialists in surgery, endoscopy, intensive care, anaesthesia, } \\
\text { gastroenterology, nutrition, and full support staff } \\
\text { A surgeon or gastroenterologist with specific knowledge of and interest in pancreaticobiliary } \\
\text { disease }\end{array}$ \\
Team leader & $\begin{array}{l}\text { Facilities for HDU/ITU management of critically ill patients including renal and respiratory support } \\
\text { Radiology }\end{array}$ \\
$\begin{array}{l}\text { Expertise permitting the use of dynamic helical or multislice CT, percutaneous needle aspiration, } \\
\text { and drainage procedures: MR and angiography are helpful but not essential }\end{array}$ \\
$\begin{array}{l}\text { Facilities for ERCP and all therapeutic endoscopy (on an emergency basis) by an experienced } \\
\text { endoscopist. } \\
\text { EUS available as an elective diagnostic procedure }\end{array}$
\end{tabular}

HDU, high dependency unit; ITU, intensive therapy unit; CT, computed tomography; EUS, endoscopic ultrasound; $M R$, magnetic resonance; ERCP, endoscopic retrograde cholangiopancreatography. 
With invited comments from MW Büchler, I Ihse, RJ Kennedy, J Slavin, D Breen (SIGGAR), S Jackson, and N King.

Conflict of interest: None declared.

Prepared by a Working Party of the British Society of Gastroenterology, Association of Surgeons of Great Britain and Ireland, Pancreatic Society of Great Britain and Ireland, and Association of Upper GI Surgeons of Great Britain and Ireland.

\subsection{REFERENCES}

1 British Society of Gastroenterology. United Kingdom guidelines for the management of acute pancreatitis. Gut 1998;42(suppl 2):S1-13.

2 Dervenis C, Johnson CD, Bassi C, et al. Diagnosis, objective assessment of severity, and management of acute pancreatitis. Santorini consensus conference. Int J Pancreatol 1999;25:195-210.

3 Uhl W, Warshaw A, Imrie C, et al. IAP guidelines for the surgical management of acute pancreatitis. Pancreatology 2002;2:565-73.

4 Toouli J, Brook-Smith M, Bassi C, et al. Guidelines for the management of acute pancreatitis. J Gastroenterol Hepatol 2002;(Suppl 17):S15-39.

5 McKay CJ, Evans $S$, Sinclair $M$, et al. High early mortality rate from acute pancreatitis in Scotland, 1984-1995. Br J Surg 1999;86:1302-5.

6 Corfield AP, Cooper MJ, Williamson RC. Acute pancreatitis: a lethal disease of increasing incidence. Gut 1985;26:724-9.

7 Toh SK, Phillips S, Johnson CD. A prospective audit against national standards of the presentation and management of acute pancreatitis in the South of England. Gut 2000;46:239-43.

8 Bradley EL III. A clinically based classification system for acute pancreatitis. Summary of the International Symposium on Acute Pancreatitis, Atlanta, Ga, September 11 through 13, 1992. Arch Surg 1993;128:586-90.

9 Buter A, Imrie CW, Carter CR, et al. Dynamic nature of early organ dysfunction determines outcome in acute pancreatitis. Br J Surg 2002;89:298-302.

10 Johnson CD, Abu-Hilal M. Persistent organ failure during the first week as a marker of fatal outcome in acute pancreatitis. Gut 2004;53:1340-4

11 Johnson CD. ABC of the upper gastrointestinal tract. Upper abdominal pain Gall bladder, BMJ 2001;323:1170-3

12 McKay AJ, Imrie CW, O'Neill J, et al. Is an early ultrasound scan of value in acute pancreatitis? Br J Surg 1982;69:369-72.

13 Canto MI, Chak A, Stellato T, et al. Endoscopic ultrasonography versus cholangiography for the diagnosis of choledocholithiasis. Gastrointest Endosc 1998;47:439-48.

14 Hogan WJ, Sherman S, Pasricha P, et al. Sphincter of Oddi manometry. Gastrointest Endosc 1997;45:342-8.

15 Lankisch PG, Assmus C, Pflichthofer D. The clock and acute pancreatitis. Int J Pancreatol 1997;22:235-6.

16 Maes B, Hastier P, Buckley MJ, et al. Extensive aetiological investigations in acute pancreatitis: results of a 1-year prospective study. Eur J Gastroenterol Hepatol 1999;11:891-6.

17 Bank S, Indaram A. Causes of acute and recurrent pancreatitis. Clinical considerations and clues to diagnosis. Gastroenterol Clin North Am 1999:28:571-89.

18 Halvorsen FA, Ritland S. Acute pancreatitis in Buskerud County, Norway. Incidence and etiology. Scand J Gastroenterol 1996;31:411-14.

19 Appelros S, Petersson U, Toh S, et al. Activation peptide of carboxypeptidase $B$ and anionic trypsinogen as early predictors of the severity of acute pancreatitis. Br J Surg 2001;88:216-21.

20 Tenner S, Fernandez-del Castillo C, Warshaw A, et al. Urinary trypsinogen activation peptide (TAP) predicts severity in patients with acute pancreatitis. Int J Pancreatol 1997;21:105-10

21 Neoptolemos JP, Kemppainen EA, Mayer JM, et al. Early prediction of severity in acute pancreatitis by urinary trypsinogen activation peptide: a multicentre study. Lancet 2000;355:1955-60.

22 Rau B, Cebulla M, Uhl W, et al. The clinical value of human pancreas-specific protein procarboxypeptidase $B$ as an indicator of necrosis in acute pancreatitis: comparison to CRP and LDH. Pancreas 1998:17:134-9.

23 Buchler MW, Gloor B, Muller CA, et al. Acute necrotizing pancreatitis: treatment strategy according to the status of infection. Ann Surg 2000;232:619-26

24 Uhl W, Roggo A, Kirschstein T, et al. Influence of contrast-enhanced computed tomography on course and outcome in patients with acute pancreatitis. Pancreas 2002;24:191-7.

25 Beger HG, Bittner R, Block S, et al. Bacterial contamination of pancreatic necrosis. A prospective clinical study. Gastroenterology 1986;91:433-8.

26 Balthazar EJ, Freeny PC, van Sonnenberg E. Imaging and intervention in acute pancreatitis. Radiology 1994;193:297-306.

27 Eatock FC, Brombacher GD, Steven A, et al. Nasogastric feeding in severe acute pancreatitis may be practical and safe. Int J Pancreatol 2000;28:23-9

28 Kemppainen E, Sainio V, Haapiainen R, et al. Early localization of necrosis by contrast-enhanced computed tomography can predict outcome in severe acute pancreatitis. Br J Surg 1996;83:924-9.

29 King NK, Powell JJ, Redhead D, et al. A simplified method for computed tomographic estimation of prognosis in acute pancreatitis. Scand J Gastroenterol 2003;38:433-6.

30 Balthazar EJ. Acute pancreatitis: assessment of severity with clinical and CT evaluation. Radiology 2002;223:603-13.
31 Isenmann R, Rau B, Beger HG. Bacterial infection and extent of necrosis are determinants of organ failure in patients with acute necrotizing pancreatitis. Br J Surg 1999;86:1020-4.

32 Brown A, Baillargeon JD, Hughes MD, et al. Can fluid resuscitation prevent pancreatic necrosis in severe acute pancreatitis? Pancreatology 2002;2:104-7.

33 Johnson CD, Kingsnorth AN, Imrie CW, et al. Double blind, randomised, placebo controlled study of a platelet activating factor antagonist, lexipafant, in the treatment and prevention of organ failure in predicted severe acute pancreatitis. Gut 2001:48:62-9.

34 Uhl W, Buchler MW, Malfertheiner P, et al. A randomised, double blind, multicentre trial of octreotide in moderate to severe acute pancreatitis. Gut 1999:45:97-104.

35 Buchler M, Malfertheiner $\mathrm{P}, \mathrm{Uhl}$ W, et al. Gabexate mesilate in human acute pancreatitis. German Pancreatitis Study Group. Gastroenterology 1993; 104:1165-70.

36 Delcenserie R, Yzet T, Ducroix JP. Prophylactic antibiotics in treatment of severe acute alcoholic pancreatitis. Pancreas 1996;13:198-201.

37 Isenmann R, Runzi $M$, Kron $M$, et al. Prophylactic antibiotic treatment in patients with predicted severe acute pancreatitis: a placebo-controlled, double-blind trial. Gastroenterology 2004;126:997-1004.

38 Nordback I, Sand J, Saaristo R, et al. Early treatment with antibiotics reduces the need for surgery in acute necrotizing pancreatitis - a single-center randomized study. J Gastrointest Surg 2001;5:113-18.

39 Pederzoli P, Bassi C, Vesentini S, et al. A randomized multicenter clinical trial of antibiotic prophylaxis of septic complications in acute necrotizing pancreatitis with imipenem. Surg Gynecol Obstet 1993;176:480-3.

40 Sainio V, Kemppainen E, Puolakkainen $P$, et al. Early antibiotic treatment in acute necrotising pancreatitis. Lancet 1995;346:663-7.

41 Schwarz M, Isenmann R, Meyer H, et al. Antibiotic use in necrotizing pancreatitis. Results of a controlled study. Dtsch Med Wochenschr 1997; 122:356-61.

42 Bassi C, Larvin M, Villatoro E. Antibiotic therapy for prophylaxis against infection of pancreatic necrosis in acute pancreatitis (Cochrane Methodology Review). Chichester: UK, John Wiley \& Sons Ltd, The Cochrane Library, issue 4, 2003.

43 Dellinger RP, Carlet JM, Masur H, et al. Surviving Sepsis Campaign guidelines for management of severe sepsis and septic shock. Crit Care Med 2004;32:858-73.

44 Luiten EJ, Hop WC, Lange JF, et al. Controlled clinical trial of selective decontamination for the treatment of severe acute pancreatitis. Ann Surg 1995;222:57-65

45 Kalfarentzos F, Kehagias J, Mead N, et al. Enteral nutrition is superior to parenteral nutrition in severe acute pancreatitis: results of a randomized prospective trial. Br J Surg 1997:84:1665-9.

46 Windsor AC, Kanwar S, Li AG, et al. Compared with parenteral nutrition, enteral feeding attenuates the acute phase response and improves disease severity in acute pancreatitis. Gut 1998;42:431-5

47 Gupta R, Patel K, Calder PC, et al. A randomised clinical trial to assess the effect of total enteral and total parenteral nutritional support on metabolic, inflammatory and oxidative markers in patients with predicted severe acute pancreatitis (APACHE II > or =6). Pancreatology 2003;3:406-13.

48 Powell JJ, Murchison JT, Fearon KC, et al. Randomized controlled trial of the effect of early enteral nutrition on markers of the inflammatory response in predicted severe acute pancreatitis. Br J Surg 2000;87:1375-81.

49 Fan ST, Lai EC, Mok FP, et al. Early treatment of acute biliary pancreatitis by endoscopic papillotomy. N Engl J Med 1993;328:228-32.

50 Folsch UR, Nitsche R, Ludtke R, et al. Early ERCP and papillotomy compared with conservative treatment for acute biliary pancreatitis. The German Study Group on Acute Biliary Pancreatitis. N Engl J Med 1997;336:237-42.

51 Neoptolemos JP, Carr-Locke DL, London NJ, et al. Controlled trial of urgent endoscopic retrograde cholangiopancreatography and endoscopic sphincterotomy versus conservative treatment for acute pancreatitis due to gallstones. Lancet 1988;2:979-83.

52 Johnson CD. Transient organ failure is not a lethal complication of acute pancreatitis. Pancreas 2002;25:435.

53 Banks PA, Gerzof SG, Langevin RE, et al. CT-guided aspiration of suspected pancreatic infection: bacteriology and clinical outcome. Int J Pancreatol 1995; 18:265-70.

54 Gerzof SG, Banks PA, Robbins AH, et al. Early diagnosis of pancreatic infection by computed tomography-guided aspiration. Gastroenterology 1987;93:1315-20.

55 Rau B, Pralle U, Mayer JM, et al. Role of ultrasonographically guided fineneedle aspiration cytology in the diagnosis of infected pancreatic necrosis. Br J Surg 1998;85:179-84.

56 Mithofer K, Mueller PR, Warshaw AL. Interventional and surgical treatment of pancreatic abscess. World J Surg 1997;21:162-8.

57 Freeny PC, Hauptmann E, Althaus SJ, et al. Percutaneous CT-guided catheter drainage of infected acute necrotizing pancreatitis: techniques and results. AJR Am J Roentgenol 1998;170:969-75.

58 Johnson CD. Timing of intervention in acute pancreatitis. Postgrad Med $J$ 1993:69:509-15.

59 Teerenhovi O, Nordback I, Eskola J. High volume lesser sac lavage in acute necrotizing pancreatitis. Br J Surg 1989;76:370-3

60 Carter CR, McKay CJ, Imrie CW. Percutaneous necrosectomy and sinus tract endoscopy in the management of infected pancreatic necrosis: an initial experience. Ann Surg 2000;232:175-80. 